\title{
CAD/CAM: \\ FEATURES, APPLICATIONS AND MANAGEMENT
}

\author{
Peter F. Jones \\ CAD/CAM Specialist
}

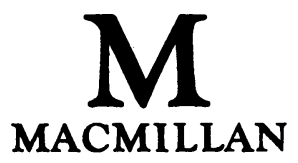


CThe Macmillan Press Ltd 1992

All rights reserved. No reproduction, copy or transmission of this publication may be made without written permission.

No paragraph of this publication may be reproduced, copied or transmitted save with written permission or in accordance with the provisions of the Copyright, Designs and Patents Act 1988, or under the terms of any licence permitting limited copying issued by the Copyright Licensing Agency, 90 Tottenham Court Road, London W1P 9HE.

Any person who does any unauthorised act in relation to this publication may be liable to criminal prosecution and civil claims for damages.

First published 1992 by

THE MACMILLAN PRESS LTD

Houndmills, Basingstoke, Hampshire RG21 2XS

and London

Companies and representatives

throughout the world

British Library Cataloguing-in-Publication Data

Jones, Peter F.

CAD/CAM: Features applications and management.

I. Title

670.285

ISBN 978-0-333-48532-3 ISBN 978-1-349-22141-7 (eBook)

DOI 10.1007/978-1-349-22141-7 
To Lelia for doing without while I was writing this, and CAD managers everywhere who have to make it all work. 


\section{Table of Contents}

List of Illustrations $\quad \mathrm{x}$

List of Tables $\quad$ xii

Preface $\quad 1$

Acknowledgements 3

Chapter 1 An introduction to computers 6

The hardware 6; The software 8; Exercise 12

Chapter $2 \mathrm{CAD} / \mathrm{CAM}$ and its value

CAD/CAM systems 13; Electronic pencil or product modeller? 14; The benefits of CAD/CAM 15; The disadvantages of CAD/CAM 18; Exercise 19

Chapter 3 The graphics screen

Graphics display limitations 21; Raster CRT displays 22;

Colour CRTs 23 ; Liquid crystal displays 24; Storage tubes 25; Vector refresh displays 25; Intelligent displays 25; Stereoscopic displays 26; The quality of colour raster CRT displays 26; The safety of CRT displays 29; Evaluating graphics screens 29; Exercise 30

Chapter 4 Interactive control devices

Pointing devices 31; The control dialogue 34; The alphanumeric CRT 36; The plasma panel and the liquid crystal display 37; Screen menus 37; Tablet menus 38; Stroke patterns 39; Voice input 40; Data input 40; The WIMP environment 41; Exercise 42

Chapter 5 Workstation layout Exercise 46

Chapter 6 Printers and plotters

Why plot out? 47; Pen plotters 48; Electrostatic plotters 53; Ink-jet plotters 54; Impact dot-matrix plotters 54; Laser printers 55; Colour transparency printers 55; Other screen copy devices 55; Making the choice 55; Exercise 56 


\section{vi Contents}

Chapter 7 The computer configuration

The central processor 59; The main memory 62; The disk memory 63; The removable storage 64; Centralised and distributed systems 69; The future of distributed systems 73; The evolution of computer configuration 74 ; Exercise 74

Chapter 8 Encoding geometry

Encoding distance 75; Encoding position 77; Scale 78; Arrays and matrices 79; Logical links and data structures 81; Exercises 81

Chapter 9 The repertoire of graphical entities

Two- or three-dimensional geometry 85; Points 86;

Straight lines 86; Circles and arcs 87, Texts 87;

Conic sections 88; Dimensions 88; Splines 89;

Surfaces 90; Solids 91; Planes 92; Invisible nongeometric entities 92; Entities aiding design 93;

Exercise 95

Chapter 10 Geometric constructions

Points 98; Arcs 102; The overlay or Boolean trim 102;

Offset 103; Two-dimensional projection aids 104;

Three-dimensional technique 104; The best repertoire

106; Surface construction 109; Exercise 110

Chapter 11 Selection facilities and transformations

Selection facilities 111; The uses of selection 112;

Transformations 113; Types of transformation 113;

Copying 119; Transformations on line ends 120; Effect of transformations on texts 120; Exercise 121

Chapter 12 Dimensioning, annotation and graphic effects Associative dimensioning 124; Annotation 124; Graphic effects 126; Exercise 126

Chapter 13 Parameterised drawing and customising

Parameterised drawing 127; Knowledge-based designs

130; Customisation 131; Exercise 132

Chapter 14 Screen handling and output facilities

Screen handling 133; Plotting facilities 139; Exercise 140 
Chapter 15 Solid modelling

Solid modelling method 142; Representing the solid in the computer 149; Faceted models 149; Modelling technique 151; Visualising objects 153; Applications of solid modelling 155; Exercise 156

Chapter 16 Numerical control program generation 157 Linking CAD to CAM 159; CAD facilities for NC 160 ; Meeting the requirements of manufacturing 162; Exercise 162

Chapter 17 Finite element analysis An approximation technique 163; Its successful application 164; The role of CAD 165; Conclusion 166 Exercise 166

Chapter 18 Schematics and electrical and electronic drawing 167 Schematics 167; Printed circuit board design 170; Integration with production 172; Exercise 173

Chapter 19 CAD data exchange standards 175 Product definition standards 176; Graphics package standards 181; Device control languages 184; Conclusion 186; Exercise 187

Chapter 20 The IGES standard

File format 189; IGES entities 191; Making IGES work 195; Exercises 198

Chapter 21 Hardware data exchange standards Half-inch magnetic tape 203; Standard character codes 205; RS232 and V24 206; Exercises 212

Chapter 22 System administration facilities Data security 213; Archiving 214; Drawing management 214; Accounting 215; Customisation and configuration 215; Plotter drivers 216; Exercise 216

Chapter 23 Robustness, reliability and support

Hardware robustness and reliability 218; Hardware support 219; Software reliability 220; Software support 222; Software robustness 223; Exercise 223 


\section{viii Contents}

Chapter 24 Making the case

The ideal scenario 225; The dilettante scenario 226;

The political scenario 227; The various kinds of benefit

228: Conclusion 232; Exercise 233

Chapter 25 Management change

Technology changing management 235; Change within the Design Department 236; Change outside the Design Department 238; CIM: CAD/CAM and integration 244; CAD/CAM features and benefits summarised 247

Chapter 26 Specifying and choosing the best system

Function 252; Performance 258; Reliability 259;

Conclusion 260; Exercises 260

Chapter 27 Conducting the procurement

To integrate or not 261; Resources for the operation 261 ; Setting the objectives 262; The procurement programme 263; The procurement team 263; The specification 264; Preliminary vendor survey 265; The invitation to tender 266; Producing the short list 267; The benchmark test 268; Negotiating the terms 269; The decision 269; Exercises 270

Chapter 28 Site planning

Cabling 271; The location of the workstations 277;

Lighting 277; Furniture 278; Cooling 278; Fire detection and control 278; Tape and disk storage 278; Dust control 279; The location of the shared equipment 279; Exercise 280

Chapter 29 Implementation

Motivation 281; Training and education 282; Site preparation, installation and acceptance 283; Preparatory drawing, customisation and cut-over 284; Review 285; Exercise 285

Chapter 30 Training, manuals and user groups

Types of training 287; Sources of user training 289;

The user group 291; Exercise 291

Chapter 31 Efficient usage

The selection of work 293; Scheduling workstations 293; 
Standards 294; Drawing management 295; People problems 295; The chores 296; Exercises 297

Chapter 32 Data Security and contingency planning 299 Ways of losing drawings 299; Back-ups 300; Archiving 303; The long-term storage of CAD drawings 304; Alternatives to tape 308; Contingency planning 308; Exercises 309

Chapter 33 Programming practice Writing for oneself and writing for others 311; The steps in producing a program 312; Exercise 315

Appendix A A checklist of features

Hardware 317; User interface 318; Systems software 319; Interactive design functions 320 ; Design automation 327

References 


\section{List of illustrations}

$\begin{array}{lll}\text { Figure } 1.1 \text { Part of a FORTRAN program } & 10\end{array}$

Figure 3.1 A cathode ray tube 22

Figure 3.2 The effect of raster scan on a line 23

Figure 3.3 A colour display 28

Figure 4.1 A CAD screen of a surface design with a screen cursor 32

Figure 4.2 A graphics tablet and pen 34

Figure 4.3 A graphics tablet and puck

Figure 4.4 A mouse 36

$\begin{array}{lll}\text { Figure } 4.5 \text { A joystick } & 37\end{array}$

Figure 4.6 A tracker ball 38

Figure 4.7 A function keypad 39

Figure 4.8 A tablet menu and puck 40

Figure 5.1 A typical workstation 44

Figure 6.1 A pen plotter - flat bed type 49

$\begin{array}{lll}\text { Figure } & 6.2 \text { A pen plotter - friction wheel type } & 50\end{array}$

Figure 6.3 A pen plotter-drum type 51

Figure 6.4 A pen plotter - roll type $\quad 52$

Figure 6.5 An electrostatic plotter 54

Figure 7.1 Standard half-inch magnetic tape 65

$\begin{array}{lll}\text { Figure } & 7.2 \text { Magnetic tape cartridges } & 66\end{array}$

$\begin{array}{lll}\text { Figure } 7.3 \text { A disk pack } & 67\end{array}$

$\begin{array}{lll}\text { Figure } 7.4 \text { A cartridge disk } & 68\end{array}$

Figure 7.5 Diskettes 69

$\begin{array}{lll}\text { Figure } 7.6 \text { A magnetic tape unit } & 70\end{array}$

$\begin{array}{lll}\text { Figure } 7.7 \text { A disk memory unit } & 71\end{array}$

$\begin{array}{llll}\text { Figure } & 8.1 & \text { Scaling factors in a CAD system } & 80\end{array}$

$\begin{array}{lll}\text { Figure } & 8.2 \text { Geometry and topology } & 82\end{array}$

$\begin{array}{lll}\text { Figure } 9.1 \text { A 3D wire-frame model } & 87\end{array}$

$\begin{array}{lll}\text { Figure } 9.2 \text { Controlling a spline curve } & 89\end{array}$

$\begin{array}{lll}\text { Figure } 9.3 \text { A ruled surface } & 91\end{array}$

Figure 10.1 Intelligent trimming - back to intersection 97

Figure 10.2 Intelligent trimming - extend to intersection 98

Figure 10.3 Intelligent trimming - foot of perpendicular 98

Figure 10.4 Defining a point - exact cursor position 99

Figure 10.5 Defining a point - nearest intersection 99

Figure 10.6 Defining a point - nearest tangent point 100

Figure 10.7 Defining a point - nearest line end 100

Figure 10.8 Defining a point - nearest midpoint 100

Figure 10.9 Defining a point - nearest centre 101

Figure 10.10 Defining a point - grid point 101

Figure 10.11 The four arcs through two points 102 
Figure 10.12 The overlay trim 103

Figure 10.13 The offset line 103

Figure 10.14 Projection in 2D 104

Figure $10.153 \mathrm{D}$ projection of a line on to a line 105

Figure $10.163 \mathrm{D}$ projection of a line on to a surface 105

Figure 10.17 The construction line method 106

Figure 10.18 The trimming method 107

Figure 10.19 The navigation method 107

Figure 10.20 The transformation method 108

Figure 11.1 Translation 114

Figure 11.2 Rotation 115

Figure 11.3 Mirroring about the horizontal 116

Figure 11.4 Mirroring about any line 116

Figure 11.5 Mirroring using mirroring about the horizontal 116

Figure 11.6 Oblique symmetry 117

$\begin{array}{lll}\text { Figure } 11.7 & \text { Differential magnification } & 118\end{array}$

$\begin{array}{lll}\text { Figure } 11.8 & \text { Shearing } & 118\end{array}$

Figure 11.9 Three-point transformation 119

Figure 11.10 Legible rotation of text 121

Figure 14.1 Perspective projection 135

Figure 14.2 Parallel projection 136

$\begin{array}{lll}\text { Figure } 14.3 \text { Exaggerated perspective } & 137\end{array}$

Figure 14.4 Windows and viewports 138

Figure 15.1 An impossible "solid" 141

$\begin{array}{lll}\text { Figure 15.2 A linear sweep primitive } & 143\end{array}$

Figure 15.3 A circular sweep primitive 143

Figure 15.4 A space curve sweep primitive 144

Figure 15.5 Use of sections 145

Figure 15.6 Use of a basket of curves 146

$\begin{array}{lll}\text { Figure } 15.7 \text { Two overlapping primitives } & 147\end{array}$

$\begin{array}{lll}\text { Figure } 15.8 & \text { Union } & 148\end{array}$

Figure 15.9 Intersection 148

Figure 15.10 Subtraction $\quad 148$

Figure 15.11 Faceted model of a cylinder $\quad 150$

Figure 15.12 Failure in faceted models - inner cylinder $\quad 150$

Figure 15.13 Failure in faceted models - result of subtraction 151

Figure 16.1 Numerically controlled machine tool programming 158

Figure 17.1 A finite element mesh 164

Figure 18.1 An electronic circuit schematic 168

Figure 18.2 The etched connections of a printed circuit board 170

Figure 18.3 The components of a printed circuit board 171

Figure 20.1 An IGES file and model 201

Figure 21.1 Magnetic tape format 204

Figure 25.1 The CAD/CAM contribution to CIM 247

Figure 32.1 A tape rotation scheme 302 


\section{List of tables}

$\begin{array}{llll}\text { Table } & 1.1 & \text { Binary codes } & 7\end{array}$

$\begin{array}{llll}\text { Table } & 2.1 & \text { Distribution of time in a Design Department } & 18\end{array}$

Table 6.1 Comparison of sheet- and roll-fed plotters 50

Table 7.1 Pipelining 62

$\begin{array}{lll}\text { Table } 8.1 \text { Coordinates of points of rectangular block } & 82\end{array}$

Table 8.2 Lines linking points of rectangular block together 83

Table 8.3 Edges bounding the faces of an object 83

Table 20.1 Global data record 191

Table 20.2 Directory entry record 192

Table 20.3 IGES geometry entities 193

Table 20.4 IGES annotation entities 194

Table 20.5 IGES structure entities 195

Table 21.1 ASCII character codes 206

Table 25.1 Information flow in design 246 


\section{Preface}

Since this book is about obtaining value from computer-aided design (CAD) it should be useful to student or established professional alike. I have had several kinds of reader in mind: those who want to start their career with a good understanding of new techniques, someone who may be drawn to the prospect of managing a CAD system, the experienced engineer who has been asked to procure or manage a new system, and the senior manager or director considering its introduction. All have an interest in the profitable use of CAD.

CAD has matured. The early exaggerated sales claims have given way, not surprisingly, to a mixture of successful applications, expensive failures and reasonable run-of-the-mill usage. To many companies it is now a normal tool to be used by designers and it is as such that it should be included in engineering courses. I have therefore treated CAD as a tool. When you use a new tool you mainly want to know what it will and will not do, and to this end it is useful to know something of how it does the job. (A knowledge that a spanner is transmitting torque provides insight on what the flats of the nut are experiencing, for example.) You also need to know not just how to use it but how to use it efficiently, and to understand the different variants of the tool and to judge its quality. (Ring spanner, open-ended spanner or box spanner and is it strong enough?). Finally, all tools in professional use need proper management to prevent them changing from valuable aids into expensive liabilities due to errors, accidents or wear. (A worn spanner can damage nuts.)

The particular outlook adopted here has led to a greater range of topics than many previous books on the subject. For instance, data security procedures and some important and little-known material on long-term data storage has been included on account of the exceptional longevity of engineering designs. The management politics of procurement is also discussed since many technical people tend to be unaware of such issues.

The book starts with an account of the way computers do their job principally for the benefit of older engineers who have not had the opportunity of understanding the basics of digital computers. Some readers will wish to omit this chapter.

The second chapter discusses some of the terms that are bandied about and the value (and pitfalls!) of using CAD.

Following these introductory chapters we describe and discuss the various items of equipment to be found in a CAD installation.

Next follows a full presentation of the many functions offered by CAD software. An effort has been made to indicate the contribution a function 
makes to the successful exploitation of CAD to allow those selecting a system to make informed judgements on what is being offered by the various vendors they are considering. The section includes a chapter on the specialised electronic CAD systems. As transferability of CAD models between companies is going to become increasingly important, three chapters on standards have been provided. Finally, the all-important but often neglected facilities to aid the management of the system are discussed and the section concludes with another vital but neglected topic: software quality, reliability and robustness.

All this material is designed to provide a good technical background to evaluating and procuring a system but procurement involves management issues and these are covered in the chapters which follow.

Finally, having procured a system, it has to be managed well to achieve results, and so the book concludes with chapters on this important aspect.

The world abounds with ill-defined buzz-phrases and acronyms amongst which are CAD and CAM (Computer-aided manufacturing). It is therefore important to say at the outset how I will be interpreting them for the purposes of this book. I am assuming that the reader will be concerned with a commercially available "CAD/CAM" system intended for use by designers. Such a system often provides facilities for the geometry defined by the designer to be converted into control instructions for numerically controlled machine tools. This process is described and its relationship with manufacturing procedures is discussed but the detail of part programming machine tools is not covered on the grounds that it is usually the concern of manufacturing specialists. Designers need to know how their CAD models may be used to supply data to Manufacturing but they will not normally be involved in actually programming the machine tools.

Peter F Jones January 1992 


\section{Acknowledgements}

When attempting to cover a wide area such as CAD/CAM, you can either farm out chapters to other authors or attempt to do the whole job yourself. If you do the latter there will always be some topics where you need to consult colleagues for their knowledge and experience. I am therefore grateful to those at Cranfield Institute of Technology and elsewhere who have allowed me to pick their brains. In addition, I am grateful to those who have provided material for illustrations and those who have read parts of the draft to check the level of presentation.

The CIM Institute Mr Peter Stokes, the Chief Executive, gave permission to use the institute's facilities in preparing the book, and read and commented on the draft.: The IBM Document Composition Facility, with which the book was typeset and the IBM Catia CAD system and DisplayGraphics personal computer graphics program contributed to the later stages of the book which was produced, with the exception of certain pictures of equipment drawn by a professional illustrator and two pictures copied from manuals, entirely electonically. The text was written using the Generalised Markup Language. This allowed full transferability between the personal computer, where the text was originated and the mainframe, where it was formatted to the typographical specification of Macmillan.

Dr Stephen Evans made a valuable contribution to the chapter on numerical control from his experience of setting up numerical control systems in industry.

Mr Raymond Goult provided a valuable introduction to IGES and STEP from his work on the international standardisation committees.

Ms Elizabeth McLellan contributed much useful information on numerical control programming from her experience in teaching and carrying out numerical control programming and in writing post-processors.

Mr Frank Ainscow contributed a very useful account of the problems in designing and manufacturing colour cathode ray tube displays while on secondment to Cranfield Institute of Technology from IBM.

Mr John Heath contributed useful information on the characteristics of magnetic media and introduced me to the valuable US Bureau of Standards report on the topic. I am also grateful to all those who have provided 
discussion and comment on various portions of the book including $\mathrm{Dr}$ Peter Deasley, Dr Victor Newman, Dr David Kirk, Mr Paul King, Mr Peter White and Mr Bob Almond. The photographs of equipment were taken at the CREATE design consultancy at Cranfield. Mr Harry Wall assisted in setting up the printing software while at the IBM office in Warwick. 